\title{
Myocardial revascularization: factors intervening in the reference and counter-reference in the hospital setting
}

\author{
Revascularização miocárdica: fatores interventores na referência e contrarreferência no cenário hospitalar
}

Revascularización miocárdica: factores interventores en la referencia y contrarreferencia en el escenario hospitalario

\section{Kamylla Santos da Cunha', Carolina Kahl', Cintia Koerich', Gabriela Marcellino de Melo Lanzoni", Alacoque Lorenzini Erdmann', Betina Hörner Schlindwein Meirelles'}

' Universidade Federal de Santa Catarina. Florianópolis, Santa Catarina, Brazil.

"Hospital Infantil Joana de Gusmão, Instituto de Cardiologia de Santa Catarina. São José, Santa Catarina, Brazil.

How to cite this article:

Cunha KS, Kahl C, Koerich C, Lanzoni GMM, Erdmann AL, Meirelles BHS. Myocardial revascularization: factors intervening in the reference and counter-reference in the hospital setting. Rev Bras Enferm [Internet]. 2018;71(4):1817-24. DOI: http://dx.doi.org/10.1590/0034-7167-2017-0218

Submission: 04-06-2017 Approval: 07-03-2017

\begin{abstract}
Objective: To understand the intervening factors in the process of reference and counter-reference of the individual with heart disease in the scenario of high complexity in the health care network. Method: Research anchored in the Grounded Theory (Teoria Fundamentada nos Dados). It totaled 21 participants. The data collection scenario was a cardiovascular reference hospital in the south of Brazil and occurred between March and June 2014. Results: The intervening factors in the reference process were the difficulty to access the points of the network and telemedicine and the central to manage the flow of patients in the network. In the counter-reference, there was a link with the hospital and the lack of communication among network professionals. Conclusion: It reveals the need to reorganize the service flow in $\mathrm{HCN}$, enhancing PHC, expanding the performance of medium complexity and increasing the capacity of high complexity in order to carry out the process of reference and counter-reference. Descriptors: Myocardial Revascularization; Access to Health Services; Integrality in Health; Health Management; Nursing.
\end{abstract}

\section{RESUMO}

Objetivo: Compreender os fatores interventores no processo de referência e contrarreferência do indivíduo com cardiopatia no cenário da alta complexidade na rede de atenção à saúde. Métodos: Pesquisa ancorada na Teoria Fundamentada nos Dados. Totalizou 21 participantes. O cenário de coleta de dados foi um hospital referência cardiovascular no sul do Brasil e ocorreu entre março e junho de 2014. Resultados: Evidencia-se como fatores interventores no processo de referência a dificuldade de acesso aos pontos da rede e a telemedicina e a central de regulação para gestão do fluxo de pacientes na rede. Na contrarreferência, o vínculo com o hospital e a ausência de comunicação entre os profissionais da rede. Conclusão: Revela a necessidade de reorganização do fluxo de atendimento na RAS, potencializando a APS, expandindo a atuação da média complexidade e ampliando a capacidade da alta complexidade a fim de efetivar o processo de referência e contrarreferência. Descritores: Revascularização Miocárdica; Acesso aos Serviços de Saúde; Integralidade em Saúde; Gestão em Saúde; Enfermagem.

\section{RESUMEN}

Objetivo: Comprender los factores interventores en el proceso de referencia y contrarreferencia del individuo con cardiopatía en el escenario de la alta complejidad en la red de atención a la salud. Métodos: Investigación anclada en la Teoría Fundamentada en Datos. Totalizó a 21 participantes. El escenario de recolección de datos fue un hospital referencia cardiovascular en el sur de Brasil y ocurrió entre marzo y junio de 2014. Resultados: Se evidencia como factores interventores en el proceso de referencia la dificultad del acceso a los puntos de la red y la telemedicina y la central de regulación para gestión del flujo de pacientes en la red. En la contrarreferencia, el vínculo con el hospital y la ausencia de comunicación entre los profesionales de la red. Conclusión: Se revela la necesidad de reorganización del flujo de atención en la RAS, potenciando la APS, expandiendo la 
actuación de la media complejidad y ampliando la capacidad de la alta complejidad a fin de ejecutar el proceso de referencia y contrarreferencia.

Descriptores: Revascularización Miocárdica; Acceso a los Servicios de Salud; Integralidad en Salud; Gestión de la Salud; Enfermería.

\section{INTRODUCTION}

Cardiovascular diseases (CVDs) lead the list of Non-Communicable Chronic Diseases and is responsible for the leading causes of death at national and global levels ${ }^{(1)}$. Although CVDs risk factors can be prevented through lifestyle management and follow-up ${ }^{(2)}$, in 2015, heart failure reached 1,124,156 hospitalizations, being the third largest cause of hospitalization in the Brazilian Unified Health System (SUS) ${ }^{(3)}$.

Parallel to the increase in hospitalizations, the need for coronary artery bypass grafting (CABG) is increasing, and this is an intervention whose purpose is to correct myocardial ischemia, by obstructing coronary arteries, preserving cardiac function and extending life expectancy ${ }^{(4)}$. This panorama draws attention from the management bodies of the SUS to an expanded look at the points of the Health Care Network $(\mathrm{HCN})$ in order to identify bottlenecks to access the system that make it difficult to monitor the health of this population in a timely manner ${ }^{(5)}$.

$\mathrm{HCN}$ is based on the principle of integrality, prioritizing that health care be carried out in a longitudinal manner, referring the individual of Primary Health Care (PHC) to specialized points in situations or health problems that require appropriate technological resolution, ensuring continuity of $\operatorname{care}^{(6-7)}$. In this context, the process of reference and counter-reference within the $\mathrm{HCN}$ is a flow organizer that, through communication between the network points, seeks to integrate the system by favoring access, continuity of attention and rationalization of resources ${ }^{(8)}$. However, this flow presents weaknesses related to the inequality between the demand and the offer of specialized services ${ }^{(7)}$.

In some countries, such as Norway, most health treatments and prevention consultations occur in municipalities at the PHC level and are financed by the government. Patients are referred for specialized care when their family doctor detects the need for it. The Norwegian patient's rights law guarantees equal access to elective specialist services by defining acceptable waiting time. In this country as well as in other European countries such as Sweden, Italy, the United Kingdom, Finland, Denmark and the Netherlands, the maximum guarantees of waiting time are common ${ }^{(9)}$.

Although the $\mathrm{HCN}$ does not present restriction on the waiting time for reference to specialized services, it is important for health professionals, including nurses, who routinely manage health and nursing services, to understand factors that it make easier or more difficult the reference and counter-reference in the health services of individuals with heart disease/ $\mathrm{HCN}$ indication in $\mathrm{HCN}$. Thus, these professionals can act as managers/co-managers recognizing the need and possibility of user reference to another point in the network, ordering and guiding the paths to be covered, contributing to the resolution of health needs, favoring the flow of these patients in the various SUS services and contributing to the development and strengthening of public policies that guarantee the population's access to the necessary health services in a timely manner.

In view of the highlighted notes, this study aims to understand the intervening factors in the process of reference and counterreference of the individual with cardiopathy in the scenario of high complexity in the health care network in SUS.

\section{OBJECTIVE}

To understand the intervening factors in the process of reference and counter-reference of the individual with heart diseases in the scenario of high complexity in the health care network at SUS.

\section{METHOD}

\section{Ethical aspects}

This study is part of a macroproject entitled "Revascularized Cardiac Patient: Reference and Counter-Reference Process of the Health Services of Santa Catarina" and complied with the ethical rules of Resolution n. 466/12 of the National Health Council. The project was approved by the Committee of Ethics in Research with Human Beings of the Federal University of Santa Catarina.

To ensure the anonymity of the participants, we used letter $\mathrm{E}$ followed by the number corresponding to the interview order to designate them (E1, E2, E3 ...) and the indication of the sample group - first group (G1), second group (G2), third group (G3) - as follows: (E1G1); (E1G2); (E1G3).

\section{Theoretical-methodological reference and type of study}

Qualitative research, which used as a methodological reference the Grounded Theory, which seeks to understand the phenomena emerging from the relationships and interactions between people based on the meanings attributed by them, guiding the systematic analysis of the data in a way that structure and process are integrated ${ }^{(10)}$.

\section{Methodological procedures}

\section{Study scenario}

The data collection scenario was a cardiovascular reference hospital in the State of Santa Catarina.

\section{Data source}

This study consisted of 21 participants who were randomly selected and distributed into three sample groups, driven by a broad and core question ${ }^{(10)}$, as shown in Chart 1. 
Chart 1 - Presentation of sample groups

\begin{tabular}{|c|c|c|c|c|}
\hline Groups & Participants & Inclusion criteria & Exclusion criteria & Questions \\
\hline $\begin{array}{l}1^{\text {st }} \text { Sample } \\
\text { group }\end{array}$ & 07 patients & $\begin{array}{l}\text { Adults of both genders, with } \\
\text { indication/submitted to the } \\
\text { CABG hospitalized in the } \\
\text { hospital (random) }\end{array}$ & $\begin{array}{c}\text { Under } 18 \text { years old } \\
\text { or without clinical } \\
\text { conditions to respond to } \\
\text { the interview }\end{array}$ & $\begin{array}{l}\text { Tell me about your pre- } \\
\text { hospitalization health follow-up }\end{array}$ \\
\hline $\begin{array}{l}2^{\text {nd }} \text { Sample } \\
\text { group }\end{array}$ & $\begin{array}{l}09 \text { health professionals } \\
\text { (05 nurses, } 02 \text { doctors, } \\
01 \text { social worker and } \\
01 \text { physical educator) }\end{array}$ & $\begin{array}{l}\text { Hospital health professionals } \\
\text { who have been providing care to } \\
\text { patients who have been referred } \\
\text { to/have undergone CABG for at } \\
\text { least six months (snowball) }\end{array}$ & \multirow{2}{*}{$\begin{array}{l}\text { Professionals away from } \\
\text { work during the data } \\
\text { collection period }\end{array}$} & $\begin{array}{l}\text { How do you live the process of } \\
\text { reference and counter-reference } \\
\text { of the person with indication } \\
\text { submitted to the CABG? }\end{array}$ \\
\hline $\begin{array}{l}3^{\text {rd }} \text { Sample } \\
\text { group }\end{array}$ & $\begin{array}{l}05 \text { professionals of the } \\
\text { regulatory complex of } \\
\text { Santa Catarina }\end{array}$ & $\begin{array}{l}\text { Professionals linked to the } \\
\text { regulatory complex of Santa } \\
\text { Catarina } \\
\text { (snowball) }\end{array}$ & & $\begin{array}{l}\text { How does the State regulation } \\
\text { contribute to the process of } \\
\text { reference and counter-reference } \\
\text { of the person with indication/ } \\
\text { submitted to the CABG? }\end{array}$ \\
\hline
\end{tabular}

Note: $C A B G$ - coronary artery bypass grafting.

\section{Collection, organization and analysis of data}

The data collection and analysis occurred concomitantly between March and June of 2014 through open and individual interviews, recorded in a digital voice device.

The analysis process followed the three codifications recommended by the method: open, axial and selective coding ${ }^{(10)}$. In open coding, the data were analyzed line by line to identify each incident. Codes were generated and after grouping, they promoted the elaboration of concepts. In the axial coding, the data were regrouped, aiming to obtain a clearer and more complete explanation about the phenomenon, relating categories to their subcategories. In the phase of selective coding, the categories and subcategories found were compared and analyzed to bring out the phenomenon of this study "Emerging high complexity as a reference for the person undergoing myocardial revascularization surgery in the face of the fragility of Basic Attention in the follow-up and articulation with the other levels of attention in SUS ". This study follows the paradigmatic model composed by five components (context, causal conditions, intervening conditions, strategies and consequences). Due to the importance and relevance of the component "intervening conditions" it was decided to deepen the discussion of its discoveries ${ }^{(10)}$. Data saturation was achieved by repeating the information and consolidating the categories found ${ }^{(10)}$. These were: "Identifying fragilities in access to points of the Health Care Network in the reference process for coronary artery bypass grafting"; "Highlighting the state regulation center for management of reference flow in the health care network" and "Emerging trust bond of the patient submitted to the CABG with the high complexity and difficulties to counter-reference."

NVIVO ${ }^{\circledR}$ software was used to organize the data during encoding.

\section{RESULTS}

From the data analysis of the component "intervening conditions", three categories were revealed, elucidating the factors that intervene in the process of reference and counter-reference of the individual with cardiopathy with a focus on high complexity in health.

In the first category, "Identifying weaknesses in the access to the points of Health Care Network in the reference process for coronary artery bypass grafting", there is a difficulty in accessing PHC and the medium complexity evidenced by the prolonged time for scheduling medical appointments and because of the reduced quantification of these professionals in these scenarios. Thus, considering the severity of the clinical picture, patients end up seeking care in the hospital emergency or in the private sector. The reduced number of cardiologists in $\mathrm{HCN}$ is highlighted as the main obstacle to the reference of individuals with heart disease to high complexity, even suppressing the demand for consultations with cardiac surgeons.

The offer of consultation with a cardiac surgeon is sufficient, even abundant; nonetheless, the offer of consultation with a cardiologist is not enough.

[...] there are many patients who do not get to the cardiac surgeon because they could not see a cardiologist. (E20G3)

Another potential factor in access to CABG refers to the high demand for references from $\mathrm{PHC}$, related in this study to the lack of preparation of professionals to meet certain health problems, understood as complex and requiring specialized evaluation. Telemedicine is mentioned as a support for the PHC family doctors to instruct them and provide greater resolve, avoiding unnecessary references.

The patients reported as not having consulted with nurses in both PHC and in the medium complexity before hospital admission. Health follow-up with the Nurse is usually provided through health promotion and disease prevention programs provided by the Ministry of Health.

Structural factors also contribute to the difficulty in access to CABG, such as the few beds of clinical and surgical hospitalization, especially in the ICU. In this context, due to the severity of condition of patients arriving at the hospital, usually by emergency, the indication of emergency CABG causes hospitalized patients to wait for a longer period for CABG. 
[...] in the emergency those who arrive in a more serious condition than those hospitalized are the first to be operated, so we are behind. (E3G1)

Thus, the hospital ends up regulating internally the flow of patients to $C A B G$, including the ICU beds, considering that these beds are insufficient to meet the need for CABG detected in the institution and that the stay in this sector is prolonged due to the severe condition of the patients and associated intercurrences.

In this context, in relation to acute cases, it can be affirmed that the reference of the individual with cardiopathy practically does not happen, considering questions that involve the difficulty to access $\mathrm{HCN}$ points, such as the incipient preparation of the PHC professional to attend more complex patients, the lack of specialists in the medium complexity and the little structure in the high complexity evidenced by the lack of beds.

The second category "Highlighting the state regulation center for management of reference flow in the health care network" highlights difficulties in the management of the National Regulatory System (SISREG) for managing the reference flow in $\mathrm{HCN}$. The state of Santa Catarina has eight computerized regulation centers, distributed in health centers that regulate consultations with specialists, examinations and beds of high complexity, using SISREG as an official computerized system. In this scenario, regulators, most medical specialists, are frequently faced with inadequately completed references and requests, considering the need for details of the patient's clinical condition and the justification of the reference or examination to be regulated.

Sometimes it [regulation professional] returns the reference [to $\mathrm{PHC}$ ] to enter the clinical data of the missing request [...] also returns exams, it happens a lot. (E16G3)

In relation to the regulation of high complexity beds through the SISREG, the non-updating of the system was pointed out as the main obstacle to its operation. Thus, the regulation of ICU beds in the State still depends on the central regulation to call the ICUs to confirm the vacancy in the system.

We see in SISREG two vacancies in ICU, but the hospital has not updated the system and these vacancies do not exist, they are occupied. (E20G3)

In summary, the central regulation is revealed as an instance with potential to manage the flow of the individual with heart disease in the $\mathrm{HCN}$, however, the poor quality of the records of references and exams and the non-updating of the occupation of beds by the professionals in the SISREG were highlighted as factors that interfere negatively in the regulatory process and consequently in the reference process of these patients.

The third category, "Emerging the bond of confidence of the patient submitted to the $C A B G$ with the high complexity and the difficulties for counter-referencing", points out the difficulties faced by high complexity professionals to counter-reference the patient after the $\mathrm{CABG}$, considering that the reference process usually does not happen and the clinical condition of this patient for PHC follow-up. This, in turn, reports the difficulty of access to PHC and medium complexity and incipient supply of services for follow-up after the CABG, resulting in the demand for the institution's own outpatient and cardiac rehabilitation department.

Newly revascularized patients are very unstable. If they are sent to the PHC, they will end up in the emergency again. (E20G3)

After clinical stability, high complexity professionals advise patients to seek PHC, but the trust bond between hospital and patient staff prevails, causing the patient to return to the hospital in the face of any need.

In the hospital and outpatient setting, nurses have their work focused on guidelines for health care during hospitalization and after discharge, including cardiac rehabilitation. However, contacting PHC staff to follow-up the post-discharge care plan is not prioritized. Thus, a weakness highlighted in the patient's counter-reference process after the CABG is communication among network professionals.

Something that would greatly help in counter-referencing is the unification of medical records and the electronic medical record, [...] where you can see the consultations, exams that the patient has already done, [...] is better than starting the follow-up from the start. (E20G3)

Thus, the use of an integrated information system available to both the State and municipalities, which would allow the visualization of patient information at any point in the network, was cited as essential to facilitate communication between $\mathrm{HCN}$ professionals and the counter-reference process.

\section{DISCUSSION}

The main barrier in the reference process of the individual with CABG cardiopathy/indication is the access to the health services evidenced in this study due to the difficulty in scheduling consultation with the family doctor in the PHC and lack of specialists in the medium complexity, in this case, the cardiologist.

The study states that the limits on accessibility to PHC are related to delays in marking consultations for family doctors and specialists, as well as inadequate service provision due to the suppressed demand at this point ${ }^{(11)}$. In this sense, when analyzing the decentralization of health management in the municipalities and its implications for the access of users in Brazil, the need for a greater number of professionals and family health teams to improve access to PHC was identified ${ }^{(12)}$. Moreover, in the United States, a study revealed the lack of physicians as a barrier to the population's access to health care at PHC, suggesting that the work of a multi-professional team and the assistance of electronic records technologies can improve access and flow in patient reference ${ }^{(13)}$.

Considering the performance of a multidisciplinary team to guarantee access, when analyzing Nursing care practices at PHC in a state in northeastern Brazil, it was observed the importance of nursing consultation for health care through dialogue and guidance, being a moment of approach and interaction with the users, facilitating the formation of bond. It evidenced the low adherence of the users to the educational activities carried 
out in the Basic Health Unit (BHU), lacking greater stimuli on the part of the nurses ${ }^{(14)}$.

A study carried out in Singapore with patients who suffered acute myocardial infarction observed that the follow-up of these patients at home, focusing on self-care before CABG, improved the physical activity index, decreased dependence, doubts regarding drug treatment, anxiety and body mass index, as well as reducing the demand for hospital emergency and medical consultation ${ }^{(15)}$, suggesting the importance of the Nurse's role in PHC.

In the PHC it was noticed that there is a need for qualification of the care mainly by the family physicians. In this context, a study affirms that qualification can occur through professional training and clinical protocols, which help the practice of these professionals and avoid references to specialists who end up overloading the system ${ }^{(16-17)}$. Experiences in Italy show that patients who receive care and are followed up in PHC services with a focus on chronic diseases, that is, qualified to meet specific demand, seek less emergency services and have less need for hospitalization than patients who do not ${ }^{(18)}$, emphasizing the need to strengthen PHC through the professional qualification to perform this support to the patient.

Also, telemedicine, as part of the services that assist in the reference of the individual with cardiopathy, seeks to provide resolution to the health care of these individuals still in $\mathrm{PHC}$, making exams reports available and enabling discussion of clinical cases between general practitioners and specialists. In the US, telemedicine is seen as a technology that can improve access to health care as well as improve the recruitment and retention of health professionals in areas away from large urban centers ${ }^{(19)}$.

Although it is not mentioned in the results of this study, for nursing, telecommunication is in the process of consolidation and regulation through the telenursing, an instrument that aims at qualifying care, enhancing the dimensions of teaching and practice, with the assistance of a specialized professional. The ethical, political, social and economic challenges of the incorporation of this tool ${ }^{(20)}$ stand out, which shows promise in Nursing care to the patient with cardiopathies in other realities, especially in the chronic condition ${ }^{(21)}$.

In this study, the lack of cardiologists in the medium complexity made it impossible to refer patients with $\mathrm{HCN}$ cardiopathy. When analyzed the mechanisms used by SUS management to guarantee access to medium complexity, this is revealed as the system's big "bottleneck" due to the scarcity of vacancies for specialist consultations ${ }^{(16)}$. This difficulty in accessing health services means that the user has to turn to private services for consultation with cardiologists and diagnostic tests, which ultimately interferes with the integral health care of this population ${ }^{(22)}$.

Given the relevance of the flow of patients in the network, as recommended in the SUS, it is evident the patient's search for other services in search of access and optimization of waiting time by the CABG. The waiting time for elective treatment is the main concern of health policies in several countries of the Organization for Economic Cooperation and Development (OECD) and should include from the moment of the first consultation and diagnostic examinations until the surgery or procedure, since, the longer the morbidity, the higher the mortality in this period ${ }^{(23-24)}$. Thus, while in the USA the waiting time for most $C A B G$ patients to intervene occurs in approximately 72 hours, in the United Kingdom patients wait approximately three months ${ }^{(25)}$, which is similar to the Brazilian rates.

Regarding the problems mentioned, SUS emergency and emergency services are becoming overwhelmed, facing problems such as the insufficient supply of hospital beds, which ends up prolonging the hospitalization of patients, promoting the aggravation of emergency situations and resulting in greater morbidity and mortality, and sequelae for the user ${ }^{(26-28)}$, requiring greater investments in infrastructure and public policies that prevent the patient from seeking services of high complexity due to the worsening clinical conditions of the disease.

The State's role of ordering the distribution of health resources, goods and services is under the responsibility of the Regulatory Complex, which must adapt supply to demand through the continuous evaluation of health indicators for equitable access $^{(29)}$. In this sense, the state regulation appears in the results as a potential instrument of flow management in $\mathrm{HCN}$. It uses SISREG, a computerized system provided by the Ministry of Health, which acts as a tool for promoting equity, accessibility and completeness, which seeks to plan and organize the flow of patients for access to medium and high complexity ${ }^{(30)}$.

Highlighting the results of this study regarding the filling of references in the $\mathrm{PHC}$ and updating the beds in high complexity through the SISREG, an important issue is the training and awareness of the professionals in these scenarios. The use of protocols is a strategy for adequate reference of the patient via SISREG in PHC, aiming to facilitate communication between requesting professionals and the regulators ${ }^{(31)}$.

In the process of ensuring full and equitable access, although in this study the nurse's role in the regulation process has not been the focus of research, this has contributed to the implementation of the regulatory tools, actively participated in the elaboration of clinical protocols and classification of priority of service, as well as, occupied strategic positions that require technical and managerial dominance ${ }^{(32)}$. In this regard, nurses involved in the Regulation, point out as essential the institutional investment with the awareness and training of municipal health teams, considering as a motivating factor for the incorporation of the tool in the work dynamics and qualification of requests and references ${ }^{(32)}$.

In this study, in Rio de Janeiro, the Regulatory Central shows difficulty in the governance of high complexity beds, especially in the ICU, considering the poor distribution of beds, with a lack in the public sector and greater concentration in the metropolitan region, pointing to flaws in the flow between the points of $\mathrm{HCN}$, resulting in difficulty of access as well as in patients' reference ${ }^{(33)}$.

For the counter-reference of the patient submitted to the $\mathrm{CABG}$, the communication between the professionals in the $\mathrm{HCN}$ is cited as a primary factor. In this sense, the importance of registering and sharing information about the patient is highlighted. A study carried out in Montes Claros, state of Minas Gerais, highlights the lack of a unified medical record in $\mathrm{HCN}$ and justifies the need to implement management systems that can integrate medical records, facilitating intercommunication between health services, organizing care and contributing to resolution and completeness of care ${ }^{(34)}$, considering that the absence of a formal counter-reference mechanism for the 
patient has a direct repercussion on their health follow-up after hospital discharge ${ }^{(35)}$.

In the process of counter-referencing, the patient's relationship with the professionals of high complexity and their resistance to counter reference the patient to $\mathrm{PHC}$ is still observed. In this sense, a study that sought to evaluate the cardiological follow-up and the risk of death after hospital discharge for patients with heart failure and reduced left ventricular expulsion fraction concluded that, after discharge, patients followed by cardiologists had lower mortality in 30 days and in one year compared to those who were followed by the general practitioner (family physicians) ${ }^{(36)}$, which may justify the conduct of these professionals.

In contrast, a study conducted in southern Brazil with patients with Tuberculosis presents a care management model that can be adapted to other groups of patients with long-term care and treatment needs, as in the case of patients with CVDS. The model provides for pre-discharge nursing consultations, intra-hospital, before and after contact with the PHC Nurse, in order to pass information, schedule the first follow-up visit to the patient, and schedule the specialized service support at PHC ensuring completeness and continuity of care $^{(37)}$.

\section{Study limitations}

Although this study is limited to the scenario of high complexity in health, the results highlight the main obstacles in the reference and counter-reference process of the individual submitted to the CABG for HCN health follow-up.

Contributions to the area of nursing, health or public policy

The results provide subsidies for reorganization of the reference process and counter-reference of the individual affected by CVDS in the SUS to make their service feasible and qualified. It still presents important spaces to increase the performance of the Nurse in the various points of the $\mathrm{HCN}$, especially in the $\mathrm{PHC}$, considering its attribution of care coordinator and professional prepared to contribute to the management of the flow of patients in the pre and postoperative CABG and follow-up longitudinal.
In addition to clinical practice, nurses have positioned themselves as leaderships, occupying strategic positions with the management nucleus of the municipal regulatory complex ${ }^{(32)}$, pointing out the important contribution of nursing in linking users with PHC, as well as with the strengthening of agile and safe access to HCN health services.

\section{FINAL CONSIDERATIONS}

The result of this study presents as main intervening factor in the reference process of the individual with cardiopathy the difficulty in access for health follow-up, evidenced by the medical absence of the family in the PHC and of the cardiologist in the medium complexity, the need for $\mathrm{PHC}$ training and the lack of beds in the hospital setting.

The central regulation of the state and telemedicine are highlighted as management tools for effecting the reference process of the individual affected by CVDS, but the need for preparation and awareness of the professionals for the proper use of SISREG is evident, as well as highlighting the difficulty in regulating ICU beds.

The integrated electronic medical record was indicated as a primordial technology to facilitate the communication between the points of the network and to enable the counter-reference process of the individual submitted to the CABG before the link with the hospital care.

Finally, the study reveals the need to reorganize the flow of care in the $\mathrm{HCN}$, strengthening $\mathrm{PHC}$ to guarantee its role as a caregiver, expanding the performance of medium complexity and increasing the capacity of high complexity to facilitate access to these services and to carry out the process of reference and counter-reference of the individual affected by CVDS.

\section{FUNDING}

This study received financial support from the Foundation for Research and Innovation Support of the State of Santa Catarina (FAPESC) through process no 1459/2012.

\section{REFERENCES}

1. Ducan BB, Chor D, Aquino EML, Bensenor IM, Mill JG, Schmidt MI, et al. Chronic non-communicable diseases in Brazil: priorities for disease management and research. Rev Saúde Pública[Internet]. 2012[cited 2016 Sep 12];46(Supl):126-34. Available from: http://www.scielo.br/pdf/rsp/v46s1/17.pdf

2. Gomes CM, Capellari C, Pereira DSG, Volkart PR, Moraes AP, Jardim V, et al. Stress and cardiovascular risk: multi-professional intervention in health education. Rev Bras Enferm[Internet]. 2016[cited 2017 Apr 04];69(2):351-9. Available from: http://www. scielo.br/pdf/reben/v69n2/en_0034-7167-reben-69-02-0351.pdf

3. Brasil. Ministério da Saúde. Datasus. Sistema de informações hospitalares. Internações e valor total de internações segundo capítulo CID-10[Internet]. Brasília, DF: 2013[cited 2016 Oct 24]. Available from: http://www.datasus.gov.br

4. Gomes WJ. On - and off - pump coronary artery bypass surgery: the heart surgeon should master both techniques. Rev Bras Cir Cardiovasc[Internet]. 2012[cited 2016 Oct 24];27(2):v-viii. Available from: http://www.bjcvs.org/pdfRBCCV/en_v27n2a02.pdf

5. Lavras C. Primary health care and the organization of regional health care networks in Brazil. Saúde Soc[Internet]. 2011 [cited 2016 Oct 24];20(4):867-74. Available from: http://www.scielo.br/pdf/sausoc/v20n4/05.pdf

6. Veras RP, Caldas CP, Morra LB, Lima KC, Siqueira RC, Rodrigues RTSV, et al. Integration and continuity of care in health care network models for frail older adults. Rev Saúde Pública[Internet]. 2014[cited 2016 Oct 24];48(2):357-65. Available from: http:// www.scielo.br/pdf/rsp/v48n2/0034-8910-rsp-48-2-0357.pdf 
7. Sousa FOS, Medeiros KR, Gurgel Jr GD, Albuquerque PC. From normative aspects to the reality of the Unified Health System: revealing barriers that curtail access to the health care network. Ciênc Saúde Colet[Internet]. 2014[cited 2016 Oct 24];19(4):128393. Available from: http://www.scielo.br/pdf/csc/v19n4/1413-8123-csc-19-04-01283.pdf

8. Brasil. Conselho Nacional de Secretários da Saúde-CONASS. Atenção Primária e promoção da saúde: Coleção Progestores: para entender a gestão do SUS. Brasília: CONASS[Internet]. 2011[cited 2016 Oct 24]. Available from: http://bvsms.saude.gov.br/bvs/ publicacoes/para_entender_gestao_sus_v.3.pdf

9. Johansson KA, Nygaard E, Herlofsen B, Lindemark F. Norwegian Clinical Priority Guidelines Author Group. Implementation of the 2013 amended Patients' Rights Act in Norway: clinical priority guidelines and access to specialised health care. Health Pol[Internet]. 2017[cited 2017 Mar 10];S0168-8510(17)30035-0. Available from: https://www.ncbi.nlm.nih.gov/pubmed/28222905

10. Strauss A, Corbin J. Pesquisa qualitativa: técnicas e procedimentos para o desenvolvimento de teoria fundamentada. $2^{\mathrm{a}}$ ed. Porto Alegre: Artmed; 2008.

11. Assis MMA, Jesus WLA. Access to health services: approaches, concepts, policies and analysis model. Ciênc Saúde Colet[Internet]. 2012[cited 2016 Oct 24];17(11):2865-75. Available from: http://www.scielo.br/pdf/csc/v17n11/v17n11a02.pdf

12. Pinafo E, Carvalho BG, Nunes EFPA. Decentralization of health management: the path traveled to date, problematic points and prospects. Ciênc Saúde Colet[Internet]. 2016[cited 2017 Feb 24];21(5):1511-24. Available from: http://www.scielo.br/pdf/csc/v21n5/1413-8123csc-21-05-1511.pdf

13. Green LV, Savin S, Lu Y. Primary Care physician shortages could be eliminated through use of teams, nonphysicians, and electronic communication. Health Aff[Internet]. 2013[cited 2017 Feb 24];32(1):11-19. Available from: http://content.healthaffairs.org/ content/32/1/11.full.pdf + html

14. Santos FPA, Acioli S, Rodrigues VP, Machado JC, Souza MS, Couto TA. Nurse care practices in the Family Health Strategy. Rev Bras Enferm[Internet]. 2016[cited 2017 Mar 10];69(6):1124-31. Available from: http://www.scielo.br/pdf/reben/v69n6/0034-7167reben-69-06-1124.pdf

15. Ettema RG, Hoogendoorn ME, Kalkman CJ, Schuurmans MJ. Desenvolvimento de uma intervenção de enfermagem para preparar pacientes idosos frágeis para cirurgia cardíaca. Eur J Cardiovasc Nurs[Internet]. 2014[cited 2017 Jun 06];13(6):494-505. Available from: http://journals.sagepub.com/doi/10.1177/1474515115586904

16. Spedo SM, Pinto NRS, Tanaka OY. The difficult access to secondary health care services: São Paulo city case study, Brazil. Physis[Internet]. 2010[cited 2017 Feb 24];20(3):953-72. Available from: http://www.scielo.br/pdf/physis/v20n3/v20n3a14.pdf

17. Starfield B. Primary care: an increasingly important contributor to effectiveness, equity, and efficiency of health services SESPAS report 2012. Gac Sanit[Internet]. 2012[cited 2017 Feb 24];26(S):20-6. Available from: https://www.ncbi.nlm.nih.gov/pubmed/22265645

18. Salvadori P. Integrated patient-centered care in Community Health Centers in Italy: performance evaluation. Ig Sanita Pubbl[Internet]. 2016[cited 2017 Feb 24];72(6):555-60. Available from: https://www.ncbi.nlm.nih.gov/pubmed/28214908

19. Potter AJ, Mueller KJ, Mackinney AC, Ward MM. Effect of tele-emergency services on recruitment and retention of US rural physicians. Rural Remote Health[Internet]. 2014[cited 2017 Apr 04];14(3):2787. Available: http://www.rrh.org.au/publishedarticles/ article_print_2787.pdf

20. Dal Sasso GTM. Telenursing in Brazil: concepts and advances. J Health Inform[Internet]. 2012[cited 2017 Mar 08];4(NEsp):I. Available from: http://www.jhi-sbis.saude.ws/ojs-jhi/index.php/jhi-sbis/article/view/256/155

21. Sharma U, Clarke M. Nurses' and community support workers' experience of telehealth: a longitudinal case study. BMC Health Serv Res[Internet]. 2014[cited 2017 Feb 1];14:164-9. Available from: http://bmchealthservres.biomedcentral.com/ articles/10.1186/1472-6963-14-164

22. Romano CMC, Scatena JHG, Kehrig RT. Public-private link in the ambulatory care of high and medium complexity within the SUS: the role of the State Health Department of Mato Grosso, Brazil. Physis[Internet]. 2015[cited 2017 Mar 10];25(4):1095-115. Available from: http://www.scielo.br/pdf/physis/v25n4/0103-7331-physis-25-04-01095.pdf

23. Siciliani L, Moranb V, Borowitz M. Measuring and comparing health care waiting times in OECD countries. Health Pol[Internet]. 2014[cited 2017 Feb 1];118(2014):292-303. Available from: https://linkinghub.elsevier.com/retrieve/pii/S0168-8510(14)00226-7

24. Amado J, Bento D, Silva D, Chin J, Marques N, Gago P, et al. Changes in referral protocols for cardiac surgery: do financial considerations come at a cost? Rev Port Cardiol[Internet]. 2015[cited 2017 Feb 1];34(10):575-81. Available from: http://www. elsevier.pt/en/linksolver/ft/pii/S0870-2551(15)00131-6

25. OECD. Health at a Glance 2013: OECD Indicators[Internet]. OECD Publishing; 2013[cited 2017 Feb 1]. Available from: https:// www.oecd.org/els/health-systems/Health-at-a-Glance-2013.pdf

26. Barbosa DVS, Barbosa NB, Najberg E. Health Regulation: challenges to the Unified Health System governance. Cad Saúde Colet[Internet]. 2016[cited 2017 Feb 1];24(1):49-54. Available from: http://www.scielo.br/pdf/cadsc/2016nahead/1414-462Xcadsc-1414-462X201600010106.pdf

27. Goldwasser RS, Lobo MSC, Arruda EF, Angelo AS, Silva JRL, Salles AA, et al. Dificuldades de acesso e estimativas de leitos públicos para unidades de terapia intensiva no estado do Rio de Janeiro. Rev Saúde Pública[Internet]. 2016[cited 2017 Feb 1];50(19):1-10. Available from: https://www.ncbi.nlm.nih.gov/pmc/articles/PMC4902093/ 
28. Fuzinatto F, Waldemar FS, Wajner A, Elias CAA, Fernandez JF, Hopf JLS, et al. A clinical decision support system for venous thromboembolism prophylaxis at a general hospital in a middle-income country. J Bras Pneumol[Internet]. 2013 [cited 2017 Feb 1];39(2):138-46. Available from: http://www.scielo.br/pdf/jbpneu/v39n2/1806-3713-jbpneu-39-2-0138.pdf

29. Peiter CC, Lanzoni GMM, Oliveira WF. Healthcare regulation and equity promotion: the National Regulation System and the health access in a large municipality. Saúde Debate[Internet]. 2016[cited 2017 Mar 08];40(111):63-73. Available from: http://www.scielo. br/pdf/sdeb/v40n111/en_0103-1104-sdeb-40-111-0063.pdf

30. Pinto JR, Carneiro MGD. Avaliação do agendamento online de consultas médicas especializadas através da central de regulação do SUS. Saúde Colet[Internet]. 2012[cited 2017 Feb 1];58(1):123-8 Available http://www.redalyc.org/pdf/842/84225063005.pdf

31. Brasil. Ministério da Saúde. Conselho Nacional de Saúde. Manual de implantação de complexos reguladores. Brasília, DF: MS; 2006[cited 2017 Feb 1]. Available from: http://www1.saude.ba.gov.br/regulasaude/2009/artigos\%20regul\%C3\%A7\%C3\%A3o/ manual_complexos_reguladores.pdf

32. Peiter CC, Lanzoni GMM, Oliveira WF. Regulation in health care: the role of nurses. Rev Rene[Internet]. 2016[cited 2017 Feb 1];17(6):820-7. Available from: http://www.revistarene.ufc.br/revista/index.php/revista/article/view/2481/pdf

33. Gawryszewski ARB, Oliveira DC, Gomes AMT. Access to SUS: representations and practices of professionals developed in Regulation Centers. Physis[Internet]. 2012[cited 2017 Feb 1];22(1):119-40. Available from: http://dx.doi.org/10.1590/S0103-73312012000100007

34. Gonçalves JPP, Batista LR, Carvalho LM, Oliveira MP, Moreira KS, Leite MTS. Electronic Medical Record: a tool that can contribute to integration of Health Care Networks. Saúde Debate[Internet]. 2013[cited 2017 Feb 1];37(96):53-50. Available from: http://dx.doi. org/10.1590/S0103-11042013000100006

35. Brito MCC, Freitas CASL, Silva MJ, Albuquerque IMN, Dias MSA. Elderly health care: the referral and counter-referral system in health services. Rev Pesqui: Cuid Fundam[Internet]. 2013[cited 2016 Oct 31];6(3):1128-38. Available from: http://www.seer.unirio. br/index.php/cuidadofundamental/article/view/2878

36. Maddox TM, Ho MP. Health services research in improving the delivery of care for patients with cardiovascular diseases. Circulation[Internet]. 2017[cited 2017 Mar 1];135:403-405 Available from: https://doi.org/10.1161/CIRCULATIONAHA.116.022877

37. Coelho APC, Larocca LM, Chaves MMN, Felix JVC, Bernardino E, Alessi SM. Healthcare management of tuberculosis: integrating a teaching hospital into primary health care. Texto Contexto Enferm[Internet]. 2016[cited 2017 Mar 10];25(2):e0970015. Available from: http://www.scielo.br/pdf/tce/v25n2/0104-0707-tce-25-02-0970015.pdf 